\title{
Giant cell arteritis presenting as bilateral anterior ischemic optic neuropathy: a biopsy-proven case report in Chinese patient
}

\author{
Guohong Tian ${ }^{1,5^{*}}$ (D) Weimin Chen², Qian Chen ${ }^{1}$, Min Wang ${ }^{1,5}$, Guixian Zhao ${ }^{3}$, Zhenxin Li ${ }^{3}$ and Jiong Zhang ${ }^{4}$
}

\begin{abstract}
Background: Giant cell arteritis (GCA) is a systemic vasculitis of medium and large-size vessels and can led to permanent visual loss in elderly patients. GCA is very rare among Asians. We report a Chinese patient presenting with acute bilateral anterior ischemic optic neuropathy, and the temporal artery biopsy proved the diagnose of GCA.
\end{abstract}

Case presentation: A 77-year-old Chinese man presented with sudden bilateral blindness for 5 days with a severe headache. Funduscopic examination revealed bilateral optic disc swollen with "chalky white" pallid appearance. The blood tests showed the erythrocyte sedimentation rate (ESR) and C-reactive protein (CRP) elevated dramatically. The color duplex ultrasonography (CDUS) of the superficial temporal artery revealed the inflammation of the vessel wall as a "halo sign". The temporal artery biopsy was perfumed and the pathology revealed luminal occlusion with multinuclear giant cell infiltration. The patient was treated with intravenous methylprednisolone for 3 days and oral prednisone weaning for 12 months. The visual acuity remained no light perception at one year follow-up.

Conclusions: Although very rare in Asian, GCA can led to permanent blindness in elderly Chinese caused by anterior ischemic optic neuropathy. The noninvasive CDUS might be a promising technique for diagnose GCA in highly suspected patients.

Keywords: Giant cell arteritis, Anterior ischemic optic neuropathy, Temporal biopsy, Ultrasonography, Asian

\section{Background}

Giant cell arteritis as a common systemic vasculitis in Western adults, was seen 20 times less frequently in Asian than in Caucasian patients [1-3]. The epidemiological studies have rarely been addressed and according to Kobayashi et al., the prevalence in Japan is 1.47 per 100000 [4]. Two large sample studies in China mainland showed the clinical manifestations of GCA in Chinese patients were similar to those previously described in literature $[5,6]$. Arteritic anterior ischemic optic neuropathy (A-AION) due to GCA, which accounting for

\footnotetext{
* Correspondence: valentian99@hotmail.com

'Department of Ophthalmology, Eye Ear Nose and Throat Hospital, Fudan University, Shanghai 200031, China

${ }^{5} \mathrm{NHC}$ Key Laboratory of Myopia, Fudan University, 83 Fenyang Road,

Shanghai 200031, China

Full list of author information is available at the end of the article
}

$85 \%$ of cases of permanent vision loss [7], had not been reported in China so far, except for several presumed cases without biopsy published in non-English literature. We reported an Asian elderly patient with sudden bilateral blindness as initial symptom presented to ophthalmologist, and the afterwards biopsy convinced the pathogenesis of GCA.

\section{Case presentation}

A 77-year-old Chinese man complained of bilateral, simultaneous onset vision loss for 5 days, accompanied by severe headache on right side and jaw pain. He was a considerable healthy man in the past. The Neuro-Ophthalmological examination revealed the patient to be alert and oriented. The visual acuities were no light perception in both eyes. The pupils were dilated with no reaction to light. Slit lamp 


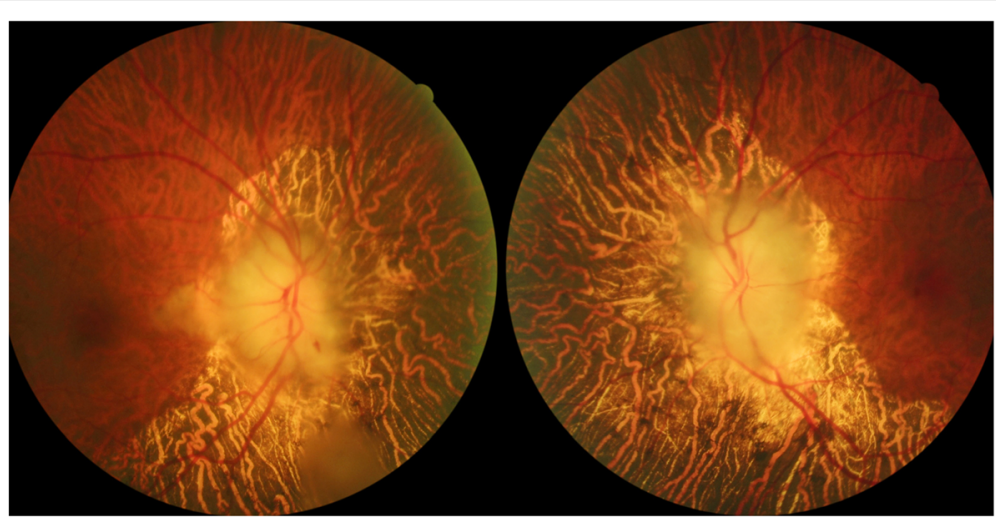

Fig. 1 Fundus photographs at presentation of the patient showing severe bilateral optic disc swollen, with "chalky white" pallid appearance; there are splinter hemorrhage and cotton wool spots on the retina in the right eye. The choroid showing diffused atrophy around the optic disc

examination showed punctate cataract and funduscopic examination revealed diffused swollen of the optic disc bilateral, with pallid "chalky white" appearance; the choroids showing diffused atrophy around the optic disc bilateral (Fig. 1). The extra-ocular motility was full of both eyes. The bilateral superficial temporal arteries were palpable and tenderness.

The routine laboratory tests showed slight decreased RBC $\left(3.09 \times 10^{12} / \mathrm{L}\right.$, normal: $\left.4-5.5\right)$ and $\mathrm{Hb}(92 \mathrm{~g} / \mathrm{l}$, normal:120-160), with normal platelet count $\left(170 \times 10^{9} / \mathrm{L}\right.$, normal:100-300);dramatic elevated erythrocyte sedimentation ratio (ESR: $100 \mathrm{~mm} / \mathrm{h}$, normal: $0-15$ ) and C-reactive protein (CRP: $39.27 \mathrm{mg} / \mathrm{L}$, normal: 0-5). The ocular blood flow detected by color duplex ultrasonography (CDUS) revealed decrease of posterior ciliary artery, central retinal artery, ophthalmic artery in both eyes. CDUS of the bilateral superficial temporal arteries with high-frequency linear probe revealed inflammation of the vessel wall as a hypo-echoic concentric ring, which referred as the "halo sign" [8] (Fig. 2). The orbital fat-suppression T1-weighted magnetic resonance imaging (MRI) with contract only showed the enhancement of the optic nerve sheath in the left eye, without inflammatory and mass occupation lesions. The MRA were also unremarkable (Fig. 3). The right temporal artery biopsy was performed and revealed the occlusion of the luminal owing to the intimal proliferation and infiltration (Fig. 4). Methylprednisolone $1 \mathrm{~g} / \mathrm{d}$ was intravenous for 3 days followed by prednisone $1 \mathrm{mg} / \mathrm{kg} / \mathrm{d}$. The vision acuity maintained NLP bilateral after treatment, whereas the headache and jaw pain disappeared. The oral prednisone was weaned and methotrexate was added as the immunosuppressive agent for long treatment. The patient was followed more than one year and there was no other new systematic symptoms, but with the permanent blindness eventually.

\section{Discussion and conclusion}

GCA represents a rare systematic granulomatous vasculitis in Asian, with fever and headache as the most prominent symptoms at onset $[5,6]$. An arteritic anterior ischemic optic neuropathy (A-AION) from inflammatory occlusion of posterior ciliary artery is the most

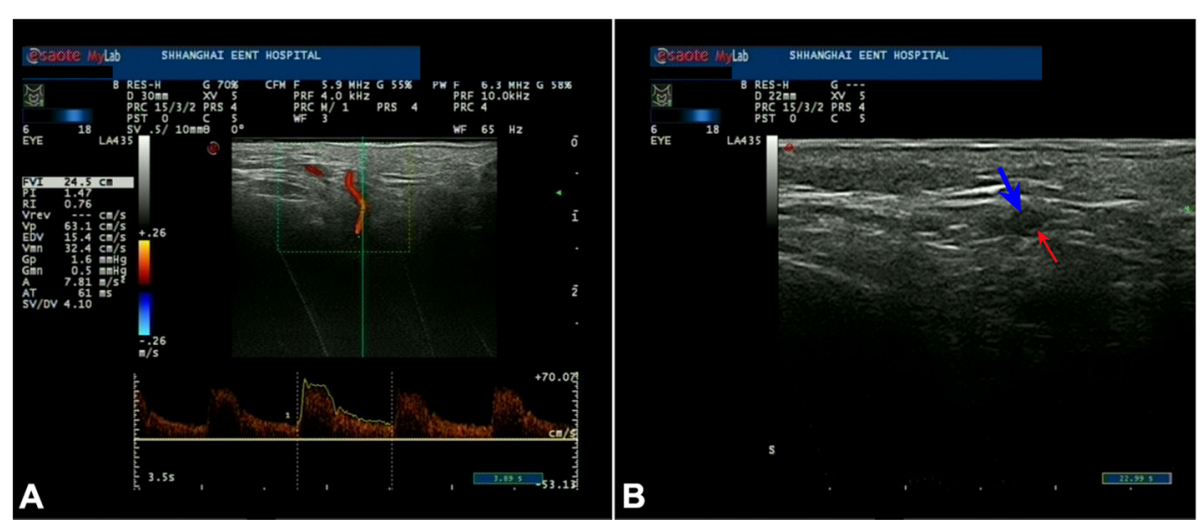

Fig. 2 The color duplex ultrasonography showing the right superficial temporal artery of the patient: (a): the accelerating of the blood flow indicate the narrowing of the vessel; $(\mathbf{b})$ : the inflammation of the vessel wall as a hypo-echoic concentric ring, which referred as the "halo sign". The blue arrow indicates the thickening vessel wall; the red arrow indicates the narrowed luminal 


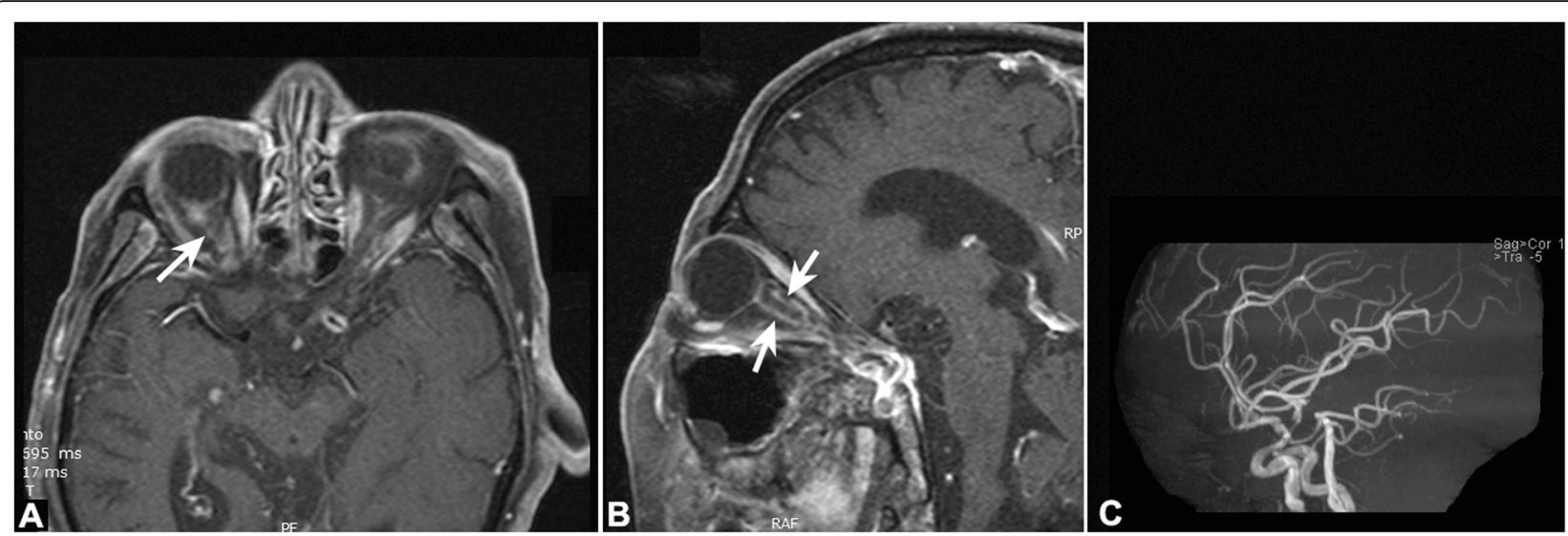

Fig. 3 The orbital fat-suppression T1-weighted magnetic resonance imaging with contract showing the enhancement of the optic nerve sheath in the right eye, (a):axial and (b): sagittal. The white arrows indicate the optic nerve sheath; the MRA of the cerebral vascular is unremarkable (c)

common cause of permanent visual loss. Attaseth et al. [9] had reported six A-AION patients in Thailand with biopsy-proven GCA and Cha et al. reported one case from Koreans [10]. To our knowledge, this is the first report of A-AION due to GCA confirmed with biopsy in Chinese patient.

The clinical features and visual outcome of our Chinese patient is not different from those described in Caucasian or Asians from Thailand and Korea [11]. The rapid progressed visual loss in elderly with headache, the "chalky white" pallid disc, as well as the evaluated ESR and CRP, the presumed GCA is not very difficult for ophthalmologists to made, even though patients without the systemic manifestation of GCA.

According to the criteria for diagnose of GCA in 1990, the biopsy is not the necessary condition, but it's still the gold standard for GCA [12]. Because of the extremely low prevalence of GCA in Asian, the other types of vasculitis such as Wegener granulomatosis, nodular polyarteritis, or Behcet disease should be as the differentiations, and polymyalgia rheumatic as an overlap with GCA. Murchison et al. suggested that all patients suspected of having GCA should undergo a temporal artery biopsy [13]. Some authors commented on the "rare" of GCA in Asian populations is likely to be under-recognized and misdiagnoses, owing to the low biopsy rate [14]. Therefor the CDUS as an noninvasive vascular imaging has an important role in the diagnostic and work-up of large-vessel vasculitis, especially in GCA patients. We also utilized the ultrasound for evaluating the superficial temporal arteries before the biopsy was performed. Using the high-frequency linear probe, the inflammation of the vessel wall can be detected as a hypo-echo concentric ring, which referred as "halo sign". More clinical evaluation and compared study will be help to obtain a normal temporal arteries normal value in Asian patients.

Although the MRI of the optic nerve would not help to differentiate the arteritic AION from the N-AION, the perio-optic nerve sheath enhancement was also observed in our patient, just as reported in Asian patients before [9]. The unremarkable diffused weighted imaging of the optic nerve of the orbit part can help ophthalmologists to exclude the posterior optic neuropathies due to other inflammatory or infiltration [15].

Because GCA is a rapid progressive irreversible blindness condition, although very rare in Asian patients, the

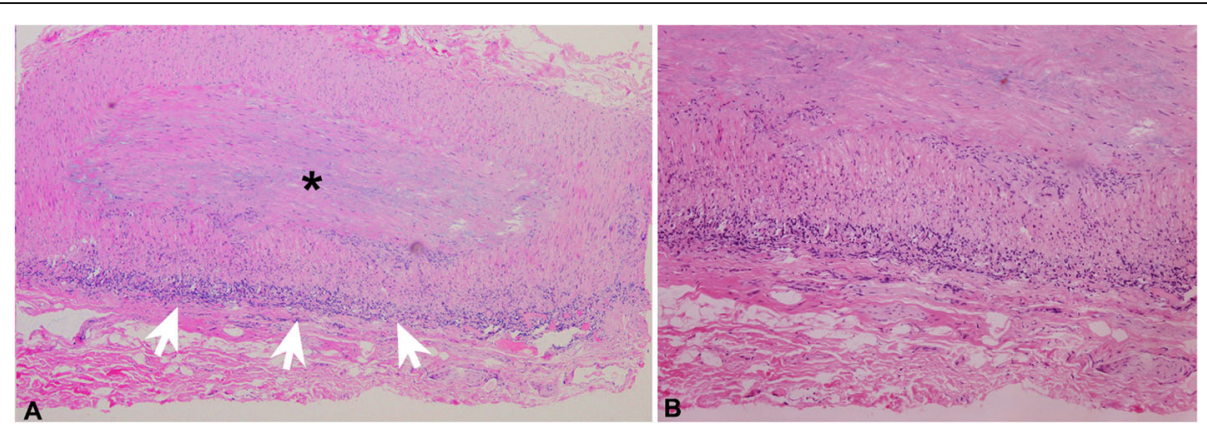

Fig. 4 Histopathology of right temporal arterial biopsy showing the almost occlusion of the luminal (asterisk), and diffused infiltration of inflammation by lymphocytes, macrophages and multinuclear giant cells in the arterial wall (white arrows). (a): H\&E $\times 40$. (b): H\&E $\times 100$ 
vigilant for quick ESR and CRP tests is very important. The high dose of corticosteroid treatment should not be delayed while waiting for the result of biopsy.

In conclusion, although A-AION due to GCA is very rare in Asian patients, the sudden devastating visual loss with headache in elderly, the white chalk pallid disc, and the evaluated ESR and CRP will differentiate it from the common N-AION type. We emphasize that noninvasive ultrasound and MRI will be a very promising methods for work-up GCA in Asian in case the biopsy is impossible.

\begin{abstract}
Abbreviations
A-AION: Arteritic ischemic optic neuropathy; AION: Anterior ischemic optic neuropathy; CDUS: Color duplex ultrasonography; CRP: C-reactive protein; ESR: erythrocyte sedimentation rate; GCA: Giant cell arteritis; MRI: Magnetic resonance imaging; N-AION: nonarteritic ischemic optic neuropathy
\end{abstract}

\section{Acknowledgements}

The authors thank Dr. Deshan Gong (Department of neurosurgery in Deji Hospital) for doing the biopsy.

\section{Funding}

Talent Doctor Project in Fudan University, Shanghai.

\section{Availability of data and materials}

All data generated or analysed during this study are included in this published article.

\section{Authors' contributions}

GT wrote the manuscript and analysis the data with reviewing the literature. WC and GZ were patient's attending physicians, who collected the clinical materials. QC collected ultrasound data and assisted in drafting manuscript. MW and ZL revised the manuscript and discussions. JZ charged the treatment of the patients and assisted in discussion. All authors read and approved the final manuscript.

\section{Ethics approval and consent to participate}

Not applicable.

\section{Consent for publication}

Written informed consent was obtained from the patient for publication of this case and any accompanying images. A copy of the written consent is available for review by the editor of this journal.

\section{Competing interests}

The authors declare that they have no competing interests.

\section{Publisher's Note}

Springer Nature remains neutral with regard to jurisdictional claims in published maps and institutional affiliations.

\section{Author details}

${ }^{1}$ Department of Ophthalmology, Eye Ear Nose and Throat Hospital, Fudan University, Shanghai 200031, China. ${ }^{2}$ Department of Neurology, Shanghai Deji Hospital, Shanghai 200010, China. ${ }^{3}$ Department of Neurology, Huashan Hospital, Fudan University, Shanghai 200040, China. ${ }^{4}$ Department of Rheumatology, Huashan Hospital, Fudan University, Shanghai 200040, China. ${ }^{5} \mathrm{NHC}$ Key Laboratory of Myopia, Fudan University, 83 Fenyang Road, Shanghai 200031, China.

Received: 9 May 2018 Accepted: 23 October 2018

Published online: 30 October 2018

\section{References}

1. Weyand $\mathrm{CM}$, Goronzy JJ. Giant-cell arteritis and polymyalgia rheumatica. Ann Intern Med. 2003;139:505-15.

2. Kale N, Eggenberger E. Diagnosis and management of giant cell arteritis: a review. Curr Opin Ophthalmol. 2010;21(6):417-22.
3. Pereira LS, Yoon MK, Hwang TN, Hong JE, Ray K, Porco T, McCulley TJ. Giant cell arteritis in Asians: a comparative study. Br J Ophthalmol. 2011;95(2):214-6.

4. Kobayashi S, Yano T, Matsumoto Y, et al. Clinical and epidemiologic analysis of giant cell (temporal) arteritis from a nationwide survey in 1998 in Japan: the frst government-supported nationwide survey. Arthritis Rheum. 2003;49(4):594-8.

5. Sun F, Ma S, Zheng W, Tian X, Zeng X. A retrospective study of Chinese patients with Giant cell arteritis (GCA): clinical features and factors associated with severe ischemic manifestations. Medicine (Baltimore). 2016;95(13):e3213.

6. Hu Z, Yang Q, Li J, Zeng S, Wu X, Cao L, Yang L, Song X. Clinical features and treatment of giant cell arteritis in Chinese. a prospective study Zhonghua Yi Xue Za Zhi. 2002 Apr 10;82(7):453-5.

7. Chen JJ, Leavitt JA, Fang C, Crowson CS, Matteson EL, Warrington KJ. Evaluating the incidence of Arteritic ischemic optic neuropathy and other causes of vision Loss from Giant cell arteritis. Ophthalmology. 2016;123(9):1999-2003.

8. Muratore F, Pipitone N, Salvarani C, Schmidt WA. Imaging of vasculitis: state of the art. Best Pract Research Clin Rheumatol. 2016;30:688-706.

9. Attaseth $T$, Vanikieti $K$, Poonyathalang A, Preechawat $P$, Jindahra $P$, Wattanatranon D. Anterior ischemic optic neuropathy due to biopsy-proven giant cell arteritis in Thai patients. Clin Ophthalmol. 2015 Jun 12;9:1071-5.

10. Cha DM, Lee T, Choe G, Yang HK, Hwang JM. Silent giant cell arteritis in an elderly Korean woman. Korean J Ophthalmol. 2013 Jun;27(3):224-7.

11. Ninan JV, Lester S, Hill CL. Diagnosis and management of giant cell arteritis: an Asia-Pacific perspective. Int J Rheum Dis. 2018 Apr 17. https://doi.org/10. 1111/1756-185X.13297. [Epub ahead of print].

12. Hunder GG, Bloch DA, Michel BA, et al. The American College of Rheumatology 1990 criteria for the classification of giant cell arteritis. Arthritis Rheum. 1990;33(8):1122-8.

13. Murchison AP, Gilbert ME, Bilyk JR, Eagle RC Jr, Pueyo V, Sergott RC, Savino PJ. Validity of the American College of Rheumatology criteria for the diagnosis of giant cell arteritis. Am J Ophthalmol. 2012;154(4):722-9.

14. Vankalakunti M, Dharmanand BG, Chandra S, Pai SA. Giant cell arteritis: a clinical and pathological study. Natl Med J India. 2010;23(1):18-20.

15. Lu P, Sha Y, Wan H, Wang F, Tian G, Tang W. Assessment of nonarteritic anterior ischemic optic neuropathy with intravoxel incoherent motion diffusion-weighted imaging using readout-segmented echo-planar imaging parallel imaging, and 2D navigator-based reacquisition. J Magn Reson Imaging. 2017:46(6):1760-6.

\section{Ready to submit your research? Choose BMC and benefit from:}

- fast, convenient online submission

- thorough peer review by experienced researchers in your field

- rapid publication on acceptance

- support for research data, including large and complex data types

- gold Open Access which fosters wider collaboration and increased citations

- maximum visibility for your research: over $100 \mathrm{M}$ website views per year

At BMC, research is always in progress.

Learn more biomedcentral.com/submissions 